https://doi.org/10.15407/ujpe64.4.348

A.N. VASILEV

Taras Shevchenko National University of Kyiv, Faculty of Physics, Chair of Theoretical Physics (60, Volodymyrs'ka Str., Kyiv 01601, Ukraine; e-mail: vasilev@univ.kiev.ua)

\title{
A MODEL OF GAS DIFFUSION IN A METAL PLATE WITH PHASE TRANSFORMATION
}

\begin{abstract}
A model of gas diffusion in a metal plate has been proposed, in which a phase transformation "metal-gassed metal" takes place, when the gas concentration exceeds a certain critical value, and the properties of the system change qualitatively. The phase transformation is modeled by changing the coefficient of gas diffusion. In particular, a system of two phases with different diffusion coefficients and a moving interface between them is considered. The gas concentrations in both phases at the interface are assumed to be the known constants. An analytical solution is obtained in the approximation that the diffusion in the metal phase (the initial state of a metal layer) is much quicker than that in the gassed-metal one, with the both being much quicker than the motion of the phase interface. In the framework of this model, the spatial distribution of the gas concentration in the gassed-metal phase is calculated, and the analytic formula describing the motion of a phase interface is derived.
\end{abstract}

Ke ywords: gas, metal, diffusion, phase transformation, moving interface.

\section{Introduction}

In this paper, the problem of gas diffusion in metal is considered. This topic remains to be of interest and promising despite its rather long history and significant advances. In particular, one of the most challenging areas of modern researches concerning the diffusion in solids is associated with the study of the hydrogen diffusion in pure metals and metallic alloys. The interest in systems of the metal-hydrogen type is stimulated by a number of factors not only of the physical origin, but also of the economical one. For example, metal-hydrogen compounds are used in nuclear engineering, while solving environmental problems, as well as in the processes of hydrogen purification and at the hydrogen storage [1-6].

The specific features of systems of the metalhydrogen type are partially connected with the fact that hydrogen atoms have a high diffusion mobility,

(C) A.N. VASILEV, 2019 which allows them to relatively easily move in metals. It is clear that, in this case, changes in the physical and chemical properties of the alloy can be expected. It is not excluded that the hydrogen diffusion in a metal can lead to phase transformations that modify its properties at the qualitative level.

As an example of such systems, let us consider a magnesium specimen, in which the diffusion-driven hydrogen transport takes place. It is known that when the mass fraction of hydrogen in magnesium exceeds $7.6 \%$, a phase transformation into a hydride state occurs (see, e.g., work [7]). From the application viewpoint (in the sense of studying the hydrogen diffusion), the metal and hydride states are strongly different with respect to the rate of diffusion in them: in the metal state, the diffusion is much quicker than in the hydride. Hence, we obtain a system with two phases, whose properties are qualitatively different.

Since the formation of a new phase is associated with the hydrogen diffusion, the matter in such cases actually concerns the expansion of the new phase in

ISSN 2071-0194. Ukr. J. Phys. 2019. Vol. 64, No. 4 
the specimen [8-11]. This problem has a long history (see, e.g., work [12]), but, owing to its complicated character, it remains challenging till now. The model proposed in this work is directly connected with this issue. Unlike the previous works dealing with numerical solutions, we will derive approximate analytic solutions, which may turn out useful not only for a quantitative, but also for qualitative analysis of systems with a moving phase interface.

\section{Model}

Let us consider the diffusion of a gas in a metal. In particular, let us consider a metal plate with thickness $L$. Accordingly, the spatial coordinate $z$ is reckoned along the axis directed perpendicularly to the plate plane $(0 \leq z \leq L)$. A gas can penetrate into the plate. A constant gas concentration $C_{L}$ is maintained at the one plate side (at $z=L$ ), and a different constant concentration $C_{0}<C_{L}$ is maintained at the other side (at $z=0$ ).

We assume that the presence of gas atoms in a metal leads to a phase transformation, which gives rise to qualitative changes in the diffusion properties of the system. The phase transformation occurs provided that the gas concentration exceeds a certain critical value $C_{s}$, which is assumed to be known. Thus, the plate is conditionally divided into two layers: the initial metal phase (at $0 \leq z<s$ ) and the new gassed phase (at $s<z \leq L$ ), the latter being a result of the phase transformation. The position of the interface between the phases is described by the coordinate $x=s$, which moves in the course of time, i.e. $s=s(t)$. The phase interface moves due to the expansion of the new phase from the right side of the plate (the coordinate $z=L$ ) toward the left side (the coordinate $z=0$ ). The gas concentration at the interface in the new gassed phase is assume to be constant and equal to $C_{s}$. The gas concentration at the interface in the metal phase is also assumed to be constant and equal to $C_{0}$, i.e. it is the same as at the left side. In effect, this means that, taking into account the rate of diffusion in the metal phase, the gas concentration in the metal phase is constant and equal to $C_{0}$. The geometry of the problem is schematically exhibited in Fig. 1.

In the general case, the system is described by equations of the diffusion type,

$\frac{\partial C_{k}}{\partial t}=D_{k} \Delta C_{k} \quad(k=1,2)$.

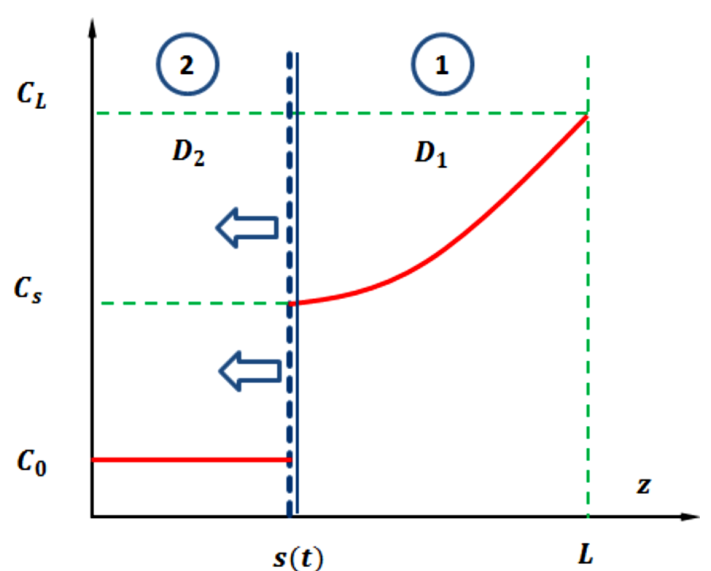

Fig. 1. At the right end of the plate, the gas concentration equals $C_{L}$. In the metal phase, the gas concentration is constant and equal to $C_{0}$. In the new gassed-metal phase, the gas concentration equals $C_{s}$ at the phase interface. Numbers 2 and 1 mark, respectively, the region of the metal phase and the plate region with the gassed-metal phase (a new phase, into which the initial metal phase transforms)

Here, $D_{k}$ is the diffusion coefficient in the $k$-th phase, and $C_{k}(t, x)$ is the gas concentration in this phase. These equations should be supplemented with boundary conditions. According to the aforesaid, they are as follows:

$C_{2}(t, 0)=C_{2}(t, s)=C_{0}$,

$C_{1}(t, s)=C_{s}$,

$C_{1}(t, L)=C_{L}$.

The specific character of the problem consists in that the phase interface is movable. As was marked above, we have to take into account that $s=s(t)$. An equation for the phase interface dynamics can be obtained from the balance equation $[7,8]$

$\frac{d s}{d t}=\frac{\left.D_{2} \frac{\partial C_{2}}{\partial z}\right|_{z=s}-\left.D_{1} \frac{\partial C_{1}}{\partial z}\right|_{z=s}}{\left.C_{1}\right|_{z=s}-\left.C_{2}\right|_{z=s}}$.

Finally, the initial condition for the function $s(t)$ is obvious and looks like

$s(0)=L$,

which means that there is no new phase at the initial moment.

Formally, the equations presented above have to be supplemented with the initial condition for the gas 
concentration distribution in the plate. However, in view of the time hierarchy of the processes, the situation can be strongly simplified. First of all, let us proceed from the fact that the diffusion processes in the metal phase are much quicker than in the new phase $\left(D_{2} \gg D_{1}\right)$ [7]. Therefore, a good approximation is obtained, if we assume that the gas distribution in the metal phase is stationary. Taking the boundary conditions into account, we set

$C_{2}(t, z) \equiv C_{0}$.

Then the equation for the dynamics of the phase interface looks like

$\frac{d s}{d t}=-\frac{\left.D_{1} \frac{\partial C_{1}}{\partial z}\right|_{z=s}}{C_{L}-C_{0}}$.

The space-time distribution of the gas concentration in the new phase (region 1 in Fig. 1) is determined by the diffusion equation - this is Eq. (1) with $k=1-$ with boundary conditions (3) and (4). It is easy to understand that, in this case, the main technical problem is associated with the fact that one of the boundaries, at which the gas concentration is given - in condition (3), this is the boundary $x=s(t)$ - is movable, because its position changes in the course of time. The problems of this type have a long history, and they are mainly solved with the help of numerical methods (see, e.g., works [7-13] and references therein). We will take another way and derive an approximate, but analytic solution. First of all, let us make the equations dimensionless.

\section{Approximate Analytic Solution}

To formalize the problem, let us introduce the following notations: the dimensionless coordinate $x=z / L$, the dimensionless coordinate of the phase interface $r=s / L$, the dimensionless gas concentration in the new gassed-metal phase $\varphi=\left(C_{1}-C_{0}\right) /\left(C_{L}-C_{0}\right)$, and the dimensionless time $\tau=t D / L^{2}$. We also introduce the dimensionless parameter $a=\left(C_{s}-C_{0}\right) /\left(C_{L}-C_{0}\right)$. In this case, the space-time distribution of the gas concentration is determined by the equation

$\frac{\partial \varphi}{\partial \tau}=\frac{\partial^{2} \varphi}{\partial x^{2}}$,

and the equation describing the motion of the phase interface reads

$\frac{d r}{d \tau}=-\left.\frac{1}{a} \frac{\partial \varphi}{\partial x}\right|_{x=r}$.
The dependence $r(\tau)$ satisfies the following equality at the initial moment $\tau=0$ :

$r(0)=1$.

The boundary conditions for the function $\varphi(\tau, x)$ look like

$\varphi(\tau, x=1)=1$

$\varphi(\tau, x=r)=a$.

To obtain the zeroth approximation $\varphi^{(0)}$ to the phase interface motion law, let us assume the rate of diffusion in the new phase (region 1 in Fig. 1) to be high in comparison with the interface velocity. In this case, we may assume (in the zeroth approximation) the concentration distribution to be stationary and described by the equation

$\frac{\partial^{2} \varphi^{(0)}}{\partial x^{2}}=0$

Making allowance for the boundary conditions (12) and (13), the corresponding solution looks like

$\varphi^{(0)}(x)=1-\frac{1-a}{1-r}(1-x)$.

Substituting it into Eq. (10), we obtain

$\frac{d r^{(0)}}{d \tau}=-\frac{1}{a} \frac{1-a}{1-r^{(0)}}$

Taking the initial condition (11) into account, we obtain the zeroth approximation for the phase interface motion law:

$r^{(0)}(\tau)=1-\sqrt{2 \tau \alpha}$,

where the parameter $\alpha$ is defined by the expression

$\alpha=\frac{1-a}{a}$.

It should be noted that the obtained relations agree well with the results of other studies (see, e.g., works $[7,8,11])$. At the same time, the zeroth approximation is rather crude, so that its correction is required. In particular, if we substitute dependence (17) into expression (15) obtained for a stationary distribution of the gas concentration, then the concentration distribution will formally depend on the time (due to the

ISSN 2071-0194. Ukr. J. Phys. 2019. Vol. 64, No. 4 
time dependence of the parameter $r$ ). However, this solution cannot be considered valid from the physical viewpoint. Namely, when obtaining it, we considered the influence of a gas distribution on the phase interface motion. But there is also a "feedback": the interface motion affects the gas concentration distribution.

In order to estimate this effect, let us express the function $\varphi$ in the following form:

$\varphi=\varphi^{(0)}+\delta \varphi$

where $\delta \varphi$ is a correction to the zeroth approximation. This correction arises owing to the phase interface motion. Then, with regard for Eq. (14), we obtain the following equation for $\delta \varphi$ :

$\frac{\partial \delta \varphi}{\partial \tau}=\frac{\partial^{2} \delta \varphi}{\partial x^{2}}-\frac{\partial \varphi^{(0)}}{\partial r} \frac{d r}{d \tau}$

Practically, this is an "exact" equation. But if the phase interface velocity is low in comparison with the rate of relaxation processes in the gassed phase, we may take the phase interface to be stationary for this equation. Then it is enough to determine a stationary solution by preliminarily substituting the expression for $d r / d \tau$ in accordance with relation (16). As a result, we obtain the following equation:

$\frac{\partial^{2} \delta \varphi}{\partial x^{2}}=\frac{(1-a)^{2}(1-x)}{a(1-r)^{3}}$

In view of the boundary conditions

$\delta \varphi(1)=\delta \varphi(r)=0$,

we can easily obtain a solution

$\delta \varphi=-\frac{(1-a)^{2}(1-x)(x-r)(2-r-x)}{6 a(1-r)^{3}}$.

Hence, we obtain the following expression for the gas concentration profile in the first approximation:

$\varphi^{(1)}=1-\frac{(1-a)(1-x)}{1-r}-$
$-\frac{(1-a)^{2}(1-x)(x-r)(2-r-x)}{6 a(1-r)^{3}}$.

Thus, the first approximation gives a nonlinear correction to the coordinate dependence of the gas concentration spatial distribution in the new phase.
With the gas concentration taken in the first approximation [Eq. (24)], the equation of phase interface motion reads

$\frac{d r^{(1)}}{d \tau}=\frac{(1-4 a)(1-a)}{3 a^{2}\left(1-r^{(1)}\right)}$

In the first approximation, we obtain

$r^{(1)}(\tau)=1-\sqrt{2 \beta \tau}$,

where the parameter $\beta$ is defined as follows:

$\beta=\frac{(1-a)(4 a-1)}{3 a^{2}}$.

Hence, both in the zeroth and first approximations, the time dependence of the phase interface coordinate [expressions (17) and (26), respectively] is of the same type, but the coefficients $\alpha$ and $\beta$ under the root sign are different. These parameters are important, because they determine the time $T$ of the full penetration of a new phase into the metal plate. In the zeroth approximation, we have

$T^{(0)}=\frac{1}{2 \alpha}=\frac{a}{2(1-a)}$.

In the first one,

$T^{(1)}=\frac{1}{2 \beta}=\frac{3 a^{2}}{2(1-a)(4 a-1)}$.

The both parameters and, hence, the time of the full penetration of a new phase depend on the parameter $a$, but those dependences are qualitatively different. This fact is illustrated in Fig. 2. The dependence $\alpha(a)$ is monotonic in contrast to the dependence $\beta(a)$. The latter has an extremum at $a=0.4$ and equals zero at $a=0.25$ and 1 . Therefore, the time dependence of the full penetration of a new phase into the plate demonstrates a qualitatively different behavior in the zeroth and first approximations. The corresponding dependences are shown in Fig. 3.

In the zeroth approximation, the time of the full penetration of a new phase monotonically decreases down to the zero value with a reduction of the parameter $a$. In the first approximation, when the parameter $a$ decreases, the time of the new phase penetration firstly decreases to a minimum value of $2 / 3$ reached at $a=0.4$ and afterward begins to increase to infinity. The value $a=0.25$ is specific: the penetration time is infinite. The specific character of this 


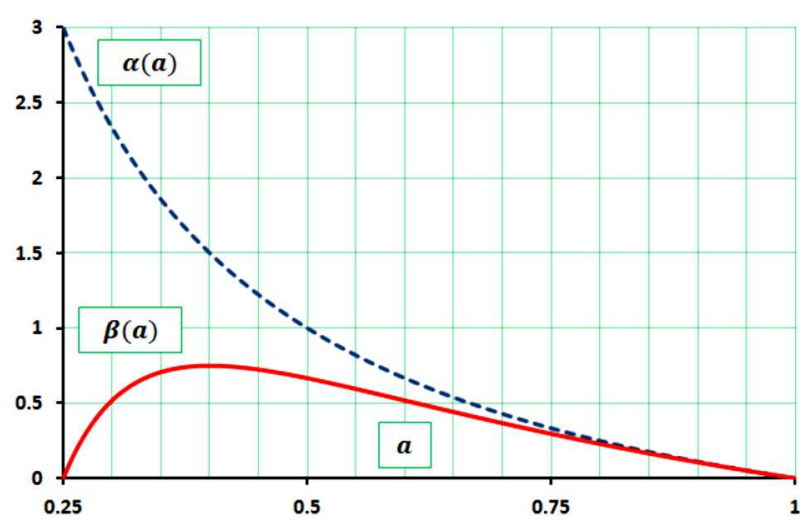

Fig. 2. Dependences of the parameters $\alpha$ (dashed curve) and $\beta$ (solid curve) on the parameter $a$

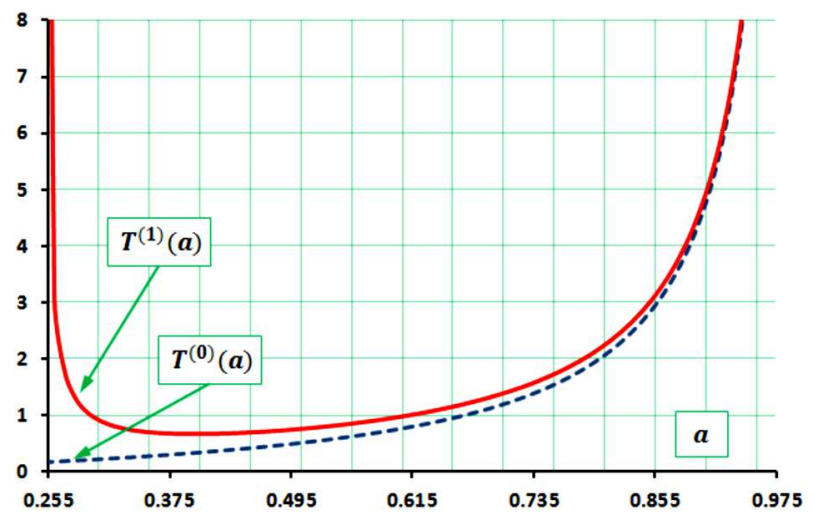

Fig. 3. Dependences of the time required for the full penetration of a new phase into the plate on the parameter $a$ : the zeroth $\left(T^{(0)}\right.$, dashed curve) and first $\left(T^{(1)}\right.$, solid curve) approximations

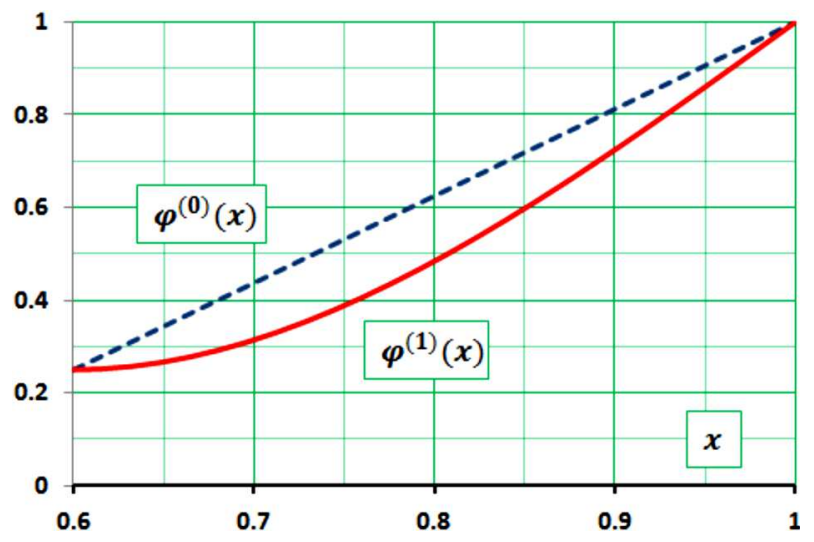

Fig. 4. Spatial distribution of the gas concentration in the new phase: the zeroth $\left(\varphi^{(0)}\right.$, dashed curve) and first $\left(\varphi^{(1)}\right.$, solid curve) approximations. The parameter values used in calculations are $r=0.6$ and $a=0.25$ value follows from the fact that, owing to a deviation of the gas concentration distribution in the new phase from the linear dependence, the gas flux through the phase interface equals zero [see formula (25)]. This case is illustrated in Fig. 4, where the profiles of the gas concentration distribution are plotted in the zeroth and first approximations. The parameter values $r=0.6$ and $a=0.25$ were used in calculations. At smaller values of the parameter $a$, the derivative of the concentration function at the interface changes its sign. In fact, this means that the value $a=0.25$ is limiting, and the model is only applicable, if $0.25<a<1$.

\section{Analysis of the Results Obtained}

Now, let us analyze the results obtained and estimate the applicability region for the proposed model. In particular, the applied approximation was based on the assumption that the phase interface velocity is much lower than the rate of diffusion in the new phase. Mathematically, this statement is expressed by the inequality

$\left|\frac{d r}{d \tau}\right| \ll 1$

From whence, taking expression (10) into account, we get the relation

$\left|\frac{\partial \varphi}{\partial x}\right|_{x=r} \ll a$.

By introducing the parameter

$\xi=1-r$

which determines the depth of penetration of the new phase into the plate, the condition of model applicability can be written as

$\xi \gg \alpha \geq \beta$.

This condition is satisfied, if

$|1-a| \ll 1$.

Hence, the quantity $|1-a|$ has to be considered as a small parameter in the framework of our approach. Then, distribution (24) can be interpreted as a series expansion in a small parameter to the second-order term. In the corresponding expression, the linear (in the small parameter) term corresponds to an approximation, in which the phase interface is fixed. The

ISSN 2071-0194. Ukr. J. Phys. 2019. Vol. 64, No. 4 
quadratic (in the small parameter) term concerns with the influence of the phase interface motion on the gas concentration distribution in the new phase.

It should also be noted that the proposed model does not describe the dynamics of the system at the initial stage of new phase formation in the metal plate. This is so because condition (33) is not satisfied, if the penetration depth $\xi$ is small, which is true at the beginning of the process. This is a long-standing problem. However, if condition (34) is obeyed, the domain, in which the model is invalid, is insignificant, and this effect can be neglected.

\section{Conclusions}

The approach proposed in this work made it possible to obtain an analytic approximation for the gas concentration profile in the new phase. This solution involves both the influence of a gas flux on the phase interface position and the influence of the interface motion on the gas concentration distribution in the new phase. In particular, it is shown that the phase interface motion leads to a nonlinear distribution of the gas concentration in the new gassed-metal phase. The calculated analytic dependences agree, at least at the qualitative level, with the available experimental data and the results of numerical calculations $[6-8,12]$. Therefore, there are grounds to believe that the results obtained, as well as the general methodology, can be useful, while analyzing experimental results and predicting the properties of relevant systems.

The author expresses his sincere gratitude to A.M. Lakhnyk for helpful discussions and research motivation.

1. A.V. Gapontsev, V.V. Kondratyev. Hydrogen diffusion in disordered metals and alloys. Usp. Fiz. Nauk 173, 1107 (2003) (in Russian).

2. Hydrogen in Metals III: Properties and Applications. Edited by H. Wipf (Springer, 1997).

3. G. Douglas, D. Ivey, O. Northwood. Storing energy in metal hydrides: a review of the physical metallurgy. J. Mater. Sci. 18, 321 (1983).

4. J.H. Woo, C.B. Jung, J.H. Lee, K.S. Lee. Electrochemical characteristics of nanocrystalline $\mathrm{ZrCr}_{2}$ and $\mathrm{Mg}_{2} \mathrm{Ni}$ type metal hydrides prepared by mechanical alloying. J. Alloy. Compd. 293-295, 556 (1999).

5. N. Cui, P. He, J.L. Luo. Synthesis and characterization of nanocrystalline magnesium-based hydrogen storage alloy electrode materials. Electrochim. Acta 44, 3549 (1999).
6. X. Yao, C.Z. Wu, H. Wang, H.M. Cheng, G.Q. Lu. Effects of carbon nanotubes and metal catalysts on hydrogen storage in magnesium nanocomposites. J. Nanosci. Nanotechn. 6, 494 (2006).

7. X. Yao, Z.H. Zhu, H.M. Cheng, G.Q. Lu. Hydrogen diffusion and effect of grain size on hydrogenation kinetics in magnesium hydrides. J. Mater. Res. 23, 336 (2008).

8. C. Schuh. Modeling gas diffusion into metals with a moving-boundary phase transformation. Metallurg. Mater. Trans. A 31A, 2411 (2000).

9. N. Teichman, M. Hamm, A. Pundt. Fast lateral hydrogen diffusion in magnesium-mydride films on sapphire substrates studied by electrochemical hydrogenography. Int. J. Hydrogen Energ. 43, 1634 (2018).

10. Y. Zhou, T.H. North. Kinetic modelling of diffusioncontrolled, two-phase moving interface problems. Model. Simul. Mater. Sci. Eng. 1, 505 (1993).

11. M. Martin, C. Gommel, C. Borkhart, E. Fromm. Absorption and desorption kinetics of hydrogen storage alloys. J. Alloy. Compd. 238, 193 (1996).

12. R.E. Pawel. Diffusion in a finite system with a moving boundary. J. Nucl. Mater. 49, 281 (1973).

13. H. Basirzadeh, A.V. Kamyad. An approach for solving of a moving boundary problem. J. Appl. Math. Comput. 14, 97 (2004).

Received 25.12.18.

Translated from Ukrainian by O.I. Voitenko

\section{O.M. Василъєв}

МОДЕЛЮВАННЯ ДИФУЗІЇ ГАЗУ

В МЕТАЛЕВІЙ ПЛАСТИНЦІ ЗА НАЯВНОСТІ ФАЗОВОГО ПЕРЕТВОРЕННЯ

Р е $з$ ю м е

В статті пропонується модель, яка описує дифузію газу в металевій пластинці. Модель базується на припущенні, що при проникненні газу в метал, коли концентрація газу перевищує певне критичне значення, відбувається фазове перетворення, в результаті чого властивості системи змінюються якісним чином. В рамках моделі наявність фазового перетворення враховується через зміну значення коефіцієнта дифузії газу в металі. Зокрема, розглядається система, що складається з двох фаз, які відрізняються значенням коефіцієнта дифузії, а границя поділу цих фаз рухається внаслідок дифузії газу. Також у моделі припускається, що на границі поділу фаз концентрація газу в кожній фазі фіксована і $є$ відомою. Аналітичний розв'язок отримано в наближенні, що швидкість дифузійних процесів у металевій фазі (вихідний стан металевого зразка) значно більша за швидкість дифузійних процесів у газованій фазі (виникає внаслідок фазового перетворення), а остання значно більша за швидкість руху границі поділу фаз. На основі моделі розраховано профіль просторового розподілу концентрації газу у газованій фазі та отримано аналітичну залежність для закону руху границі поділу фаз. 